\title{
Seal capability of interim post and core crown with temporary cements
}

\author{
Guilherme Bönecker-Valverde ${ }^{(a)}$ \\ Claudio Maniglia-Ferreira(b) \\ Gisele Priscila Abi-Rached(c) \\ Brenda Paula Figueiredo de \\ Almeida Gomes ${ }^{(d)}$ \\ Marcelo Ferraz Mesquita(e)
}

\footnotetext{
(a) PhD Student; (e)Professor - Department of Periodontics and Prosthodontics, Piracicaba Dental School, University of Campinas - UNICAMP, Piracicaba, SP, Brazil.

(b) Assistant Professor, Department of Endodontics, Health Science Center, University of Fortaleza - UNIFOR, Fortaleza, CE, Brazil.

(c) MS Student; (d) Associate Professor - Endodontics Division, Piracicaba Dental School, University of Campinas - UNICAMP, Piracicaba, SP, Brazil.
}

\begin{abstract}
The purpose of the present study was to evaluate the in vitro seal capability of interim post and core crown restorations. Eighty teeth were selected and divided into 8 groups. Four experimental groups received interim posts and core crowns. Half of each group was decoronated at the cementum-enamel junction, groups PCCH and PCZO. The other half was sectioned $2 \mathrm{~mm}$ coronal to the cementum-enamel junction, groups $\mathrm{PCrZO}$ and $\mathrm{PCrCH}$. The interim post and core crowns were luted with Rely X Temp NE, groups PCrZO and PCZO; Hydro C was used for Groups PCrCH and PCCH. The control groups, PC and PCr, received uncoated post and core crowns; groups OTg and OT were left without interim post and core crowns and were totally open. Infiltration was accessed by dye exposure followed by demineralization of the teeth. The length of the infiltration was measured using digital images taken from the specimens. The images were inserted into the Image Tool 3.0 software. Kruskal-Wallis analysis of variance and Dunn's multiple comparison method were used to test for significant differences among test groups $(P<.05)$. Groups $\mathrm{PCrZO}$ and $\mathrm{PCrCH}$ showed the least dye penetration, followed by groups $\mathrm{PCZO}$ and $\mathrm{PCCH}$. Teeth restored with interim post and core crowns will be subject to leakage. Ethics Committee: $095 / 2008$.
\end{abstract}

Descriptors: Dental leakage; Dental restoration failure; Post and core technique.

\section{Introduction}

Coronal leakage has been cited as a primary cause of inflammatory periradicular pathosis due to the penetration of bacteria into the pulp space, ${ }^{1,2}$ therefore, greater emphasis has been placed on the quality of final and interim restorations. ${ }^{3,4}$ Delay in placing a restoration, fracture of a restoration, post space preparation, or restoration failure are some of the causes for loss of coronal seal after endodontic therapy. ${ }^{5}$

Custom made posts remain an integral component of the prosthodontics treatment, ${ }^{6-8}$ especially when extensive loss of coronal tooth structure is found, and the classic extracoronal ferrule effect is suitable to improve the structural integrity of the pulpless tooth. ${ }^{9}$ When such a restoration is used, an interim post and core crown is required while the definitive restoration is being constructed. ${ }^{10}$ Therefore, not only should the criteria for construction and marginal accuracy be respected, but should also be regarded as important to seal the root canal system. ${ }^{11}$
Received for publication on Jan 05, 2010 Accepted for publication on Apr 29, 2010 
Provisional cements are used with interim restorations to provide a seal to prevent marginal leakage. They must be strong enough to retain the restoration but weak enough to enable removal of the restoration without causing damage to the abutment. ${ }^{12}$ However, interim crowns luted with provisional cements are susceptible to cement washout, marginal leakage, bacterial infiltration, and caries, especially when placed for periods longer than a few weeks. ${ }^{13}$

Torabinejad et al. ${ }^{14}$ (1990) found that bacterial recontamination along the entire length of a coronally unsealed root-filled tooth can occur within 19 days. Hence, the marginal accuracy of the interim post and core crown should be respected and an adequate provisional cement chosen. One might question the degree to which an interim post and core crown is capable of preventing penetration of bacteria into the root canal system while the patient is waiting for the final restoration..$^{15}$ Many authors have examined coronal microleakage with respect to gutta-percha root fillings and coronal plastic restorations ${ }^{16}$ but few have investigated to what degree coronal seal may be afforded by interim post and core crowns.

Therefore, the present study intends to examine the coronal seal achieved by interim post and core crowns cemented with two types of provisional cements currently used in the practice of prosthodontics, in ferruled and non-ferruled teeth. The null hypothesis was that there would be no statistically significant differences in infiltration between ferruled and non-ferruled teeth, nor between the two types of provisional cements.

\section{Material and Methods}

This study was submitted to and approved by the Human Volunteers Research and Ethics Committee of the Piracicaba Dental School (095/2008). A total of 80 uniradicular anterior teeth with similar lengths, approximately $18-19 \mathrm{~mm}$, were selected and randomly divided into 8 groups: four experimental groups, $\mathrm{PCrZO}, \mathrm{PCrCH}, \mathrm{PCZO}$ and $\mathrm{PCCH}$ $(\mathrm{n}=10)$; and four control groups, OTg, PC, PCr, and OT $(\mathrm{n}=10)$. Among the experimental groups, half were decoronated at the cementum-enamel junction using a \#3203 diamond bur (KG Sorensen, São Paulo, SP, Brazil) with continuous water cooling. The other half was sectioned coronally to the cementum-enamel junction, leaving $2 \mathrm{~mm}$ of intact tooth structure. Among the control groups, one group was left with $2 \mathrm{~mm}$ of intact tooth structure. The other three groups had their coronal structure removed at the cementum-enamel junction.

The experimental and control groups are illustrated in Figure 1. The two provisional cements used were Rely X Temp NE (3M/ESPE, St. Paul, Minn., USA), a zinc oxide non-eugenol cement, and Hydro C (Dentsply, International Inc., Milford, Del., USA), a calcium hydroxide-based cement.

Group PCrZO received interim post and core crowns cemented with Rely X Temp NE, and was left with $2 \mathrm{~mm}$ of coronal tooth structure above the crown margin. Group $\mathrm{PCrCH}$ received interim post and core crowns cemented with Hydro C, and was also left with $2 \mathrm{~mm}$ of coronal tooth structure above the crown margin. Group PCZO was restored with interim post and core crowns cemented with Rely X Temp NE, with no coronal tooth structure left above the crown margin. Group PCCH was restored with interim post and core crowns cemented with Hydro C, with no coronal tooth structure left above the crown margin. Group OTg was endodontically treated and was left totally open. Group PC was not endodontically-treated and received uncoated interim post and core crowns, and no coronal tooth structure was left above the crown margin. Group PCr was not endodontically treated, also received uncoated interim post and core crowns, and was left with $2 \mathrm{~mm}$ of coronal tooth structure above the crown margin. Group OT was left with ten control teeth totally open and was not endodonticallytreated.

A single operator, who removed all the remaining pulpal tissues from the root canals, executed the endodontic procedures. Apical patency was determined using K-file \#10 (Dentsply Maillefer, Ballaigues, Switzerland). The file was drawn back into the tooth until it was just visible at the apical foramen, and the working length was calculated to be $1 \mathrm{~mm}$ shorter than this. The sectioned root face was the reference point from which all measurements were 
Figure 1 - Experimental and control groups.

Experimental groups

Hydro C cement
W Rely X Temp NE cement
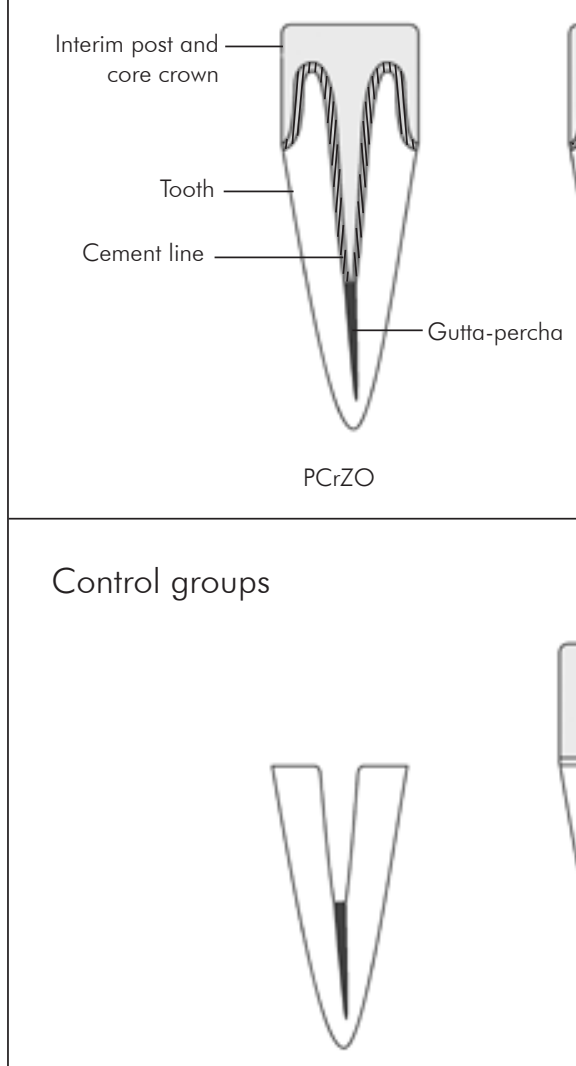

OTg

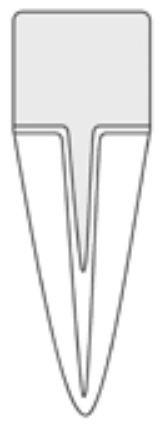

PC

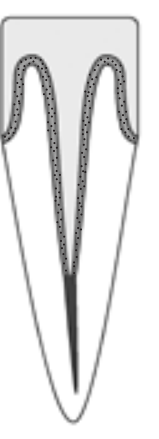

$\mathrm{PCrCH}$

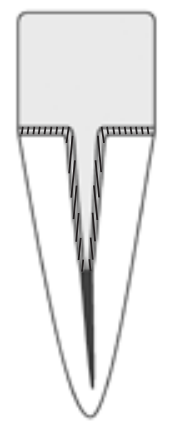

PCZO

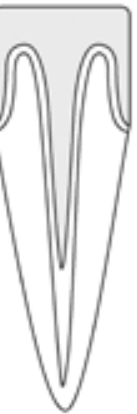

$\mathrm{PCr}$

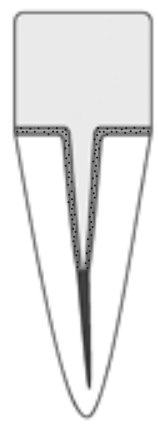

$\mathrm{PCCH}$ taken. The canals were cleaned and shaped using Gates-Glidden burs (Dentsply Maillefer, Ballaigues, Switzerland) from sizes 5 to 2 in a crown-down technique, followed by manual apical preparation with a size 45 file (K-file, Dentsply Maillefer, Ballaigues, Switzerland). All the canals were irrigated with $5 \mathrm{ml}$ of $2.5 \%$ sodium hypochlorite (Biodinâmica, Ibiporã, CE, Brazil) between each instrument, and EDTA (Biodinâmica) was used before filling the root canals for groups $\mathrm{PCrZO}, \mathrm{PCrCH}, \mathrm{PCZO}$, $\mathrm{PCCH}$ and OTg. The canals were filled with guttapercha points (Odous, Belo Horizonte, MG, Brazil) and Pulp Canal Sealer (Kerr Corp, Orange, Calif, USA) using the warm compaction technique. A final radiography was taken to ascertain the quality of the obturation. Groups PC, PCr and OT were left without endodontic obturation.

Teeth for groups $\mathrm{PCrZO}, \mathrm{PCrCH}$ and $\mathrm{PCr}$ were prepared by a single operator using a round-end, diamond-tip bur \#3145 (KG Sorensen, Barueri, SP, Brazil) and a high-speed handpiece under air-water spray. This was done to establish a chamfer finish line of $1.5 \mathrm{~mm}$ corresponding to the diameter of the bur at the level of the cementum-enamel junction; also, to establish an axial surface of coronal tooth structure of 2 millimeters 360 degrees around the circumference of the tooth preparation, to provide the ferrule effect. Groups PCZO, PCCH, OTg, PC and OT were prepared in the same way by the same operator, but without leaving coronal tooth structure above the crown margin.

Groups PCrZO, PCrCH, PCZO, PCCH and OTg had their gutta-percha removed at a length equal to $2 / 3$ of the total length of the root using a largo reamer \#2 (Dentsply Maillefer, Ballaigues, Switzerland). The correct length of the remaining api- 
cal root canal filling was measured and confirmed by radiographs. Interim post and core crowns were constructed for groups PCrZO, PCrCH, PCZO, $\mathrm{PCCH}, \mathrm{PC}$ and PCr. For that, paper clips were adjusted to fit the length of the root canal, leaving an extra portion to retain the interim crown. Retentions were added along the length of the clip and the internal area of the root canal was lubricated with petroleum jelly (União Química FTCA Nacional SA, São Paulo, SP, Brazil). A self-curing acrylic polymer (Duralay Dental Mfg Co., Worth, Ill, USA) was inserted into the canal together with the paper clip, and left to set. The crown was prepared by applying a block of acrylic resin in its doughy stage over the extra portion of the paper clip. Upon setting, the temporary post and core crown formed a single element. The external excess was removed with a maxicut bur \#1521 (Edenta, Allschwil, Switzerland) and shaped to fit perfectly the finish line of the preparation. For groups $\mathrm{PCrZO}, \mathrm{PCrCH}$ and $\mathrm{PCr}$, the interim core crowns provided a hugging action, covering the $2 \mathrm{~mm}$ of the coronal tooth structure above the crown margin. For groups PCZO, PCCH and PC, the interim core crown was accommodated over the finish line of the preparation.

Groups PCrZO and PCZO had their interim post and core crowns coated with Rely X Temp NE; groups $\mathrm{PCrCH}$ and $\mathrm{PCCH}$ were coated with Hydro C. Both cements were mixed following the manufacturer's instructions in a controlled environment room, with temperature maintained at $23 \pm 1^{\circ} \mathrm{C}$. All interim post and core crowns were cemented in place applying $5.0 \mathrm{~kg}$ pressure for $3 \mathrm{~min}$, until the cement had set. Excess cement was removed using a hand instrument.

All teeth were wrapped in moist gauze with deionized water and stored in glass vials for 7 days in incubator, at a constant temperature of $37^{\circ} \mathrm{C}$, with $100 \%$ humidity. After this period, the teeth were coated in sticky wax (Kerr Corp, Orange, Calif, USA) from the apex to the cementum-enamel junction, leaving the coronal face wax free. Each tooth was placed in a separate vial of dye at $37^{\circ} \mathrm{C}$ for 7 days. To remove any trapped air in the voids created by temporary cement dissolution, the teeth were submitted to 400 millimeters mercury vacuum pres- sure for three hours on both the first and the last days of dye infiltration.

After dye exposure, the teeth were rinsed in tap water, dried, and the sticky wax removed from the root surfaces. The teeth were submitted to demineralization in $5 \% \mathrm{HCl}$ acid for 4 days, with daily changes. ${ }^{17}$ The teeth were then cleaned with tap water and dehydrated by immersion for $24 \mathrm{~h}$ in 70,80 , 90 and $100 \%$ ethyl alcohol. Finally, the teeth were cleared and stored in methyl salicylate.

One specimen was photographed (DSC-F707, Digital Still Camera, Sony, MKM Minokamo, Japan) next to a millimeter ruler with the camera fixed on a tripod to standardize the position of the specimen and photo equipment. The image was inserted into the Image Tool 3.0 software (Department of Dental Diagnostic Science at The University of Texas Health Science Center, San Antonio, Texas, USA) to calibrate the measurement scale using the computer program. Next, all specimens were photographed the same way on their vestibular, lingual, mesial and distal faces, and the images were inserted into the same software. A single operator measured the extent of linear leakage on each face of the specimen, using a tool provided by the image tool software. Measurements were taken from the cementum-enamel junction, down the post channel, to the full depth of the dye penetration. The face having the greatest depth of penetration was used as the measure of infiltration. Data were analyzed by the Kruskal-Wallis test, and the Dunn multiple comparison was used as the post hoc test $(\alpha=.05)$.

\section{Results}

It was noted that all groups showed coronal leakage of dye. As control groups do not represent any clinical situation in practice, a non-parametric statistical test, the Kruskal-Wallis 1-way ANOVA by ranks test $(\mathrm{P}<0.001)$, was applied only to the experimental groups to provide more statistical power to the study. Significant differences were found for the experimental groups. So, an all pairwise multiple comparison procedure using Dunn's method was applied. The results are depicted in the Boxplot distribution (Graph 1). Groups PCrZO and PCZO showed statistical differences between them 


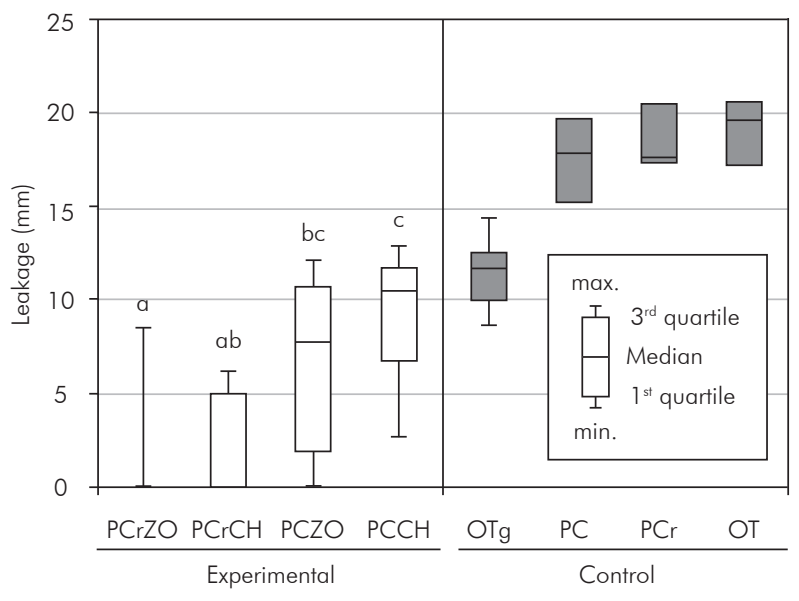

Graph 1 - Length of dye infiltration for experimental and control groups. Equal letters on the experimental groups are not considered significantly different towards infiltration.

$(\mathrm{P}<0.05)$, with median values of infiltration of $0 \mathrm{~mm}$ and $8 \mathrm{~mm}$ respectively. Groups $\mathrm{PCrCH}$ and PCCH also showed statistical differences between them, with median values of infiltration of $0 \mathrm{~mm}$ and $10 \mathrm{~mm}$. However, no differences were found between PCrZO and PCrCH $(\mathrm{P}>0.05)$, between $\mathrm{PCZO}$ and $\mathrm{PCCH}$, nor between $\mathrm{PCrCH}$ and $\mathrm{PCZO}$. The length of dye infiltration observed for each control group, PC, PCr and OT, was between approximately $15 \mathrm{~mm}$ and $20 \mathrm{~mm}$. These values were higher than any other group. However, the OTg group, also without clinical applicability, highlighted the effect of the endodontic obturation, showing values of dye infiltration varying between $9 \mathrm{~mm}$ and $15 \mathrm{~mm}$. This was lower than the other control groups, but equal or higher than the worst experimental group $(\mathrm{PCCH})$. Thus, this group became an intermediary group between the controls without cement and endodontic obturation and the experimental groups.

\section{Discussion}

The results obtained from the experimental groups support rejecting the null hypothesis that there is no statistical significant difference in infiltration between ferruled and non-ferruled teeth. However, they do not support rejection when the type of cement is considered. The control groups were used for reference and, as expected, their results showed low variability. It was observed that teeth from the groups $\mathrm{PC}$ and $\mathrm{PCr}$ showed similar results to those of the group OT. This similarity indicates that provisional cements, associated with interim post and core crowns in root-treated canals, work as a barrier toward infiltration and minimize leakage. This factor can be clearly seen when any experimental group is compared to the PC and PCr control groups, showing lower values of infiltration. The coronal tooth structure above the crown margin together with luted post and core crowns promoted a better seal. This is probably due to the more extended line of cement provided by the $2 \mathrm{~mm}$ of coronal tooth structure, causing the interim post and core crown to have a "hugging action". This extracoronal bracing has been reported by many authors ${ }^{9,10}$ to prevent fracture of the tooth structure when custom made posts and cores are used together with a cast crown. This is known as the ferrule effect, and in this case was responsible for a better seal.

The solubility of cements also plays an important role in providing a better seal. It can be considered a primary cause of failure of cast restorations, thus contributing to recurrent caries and/or loss of retention. ${ }^{13,18}$ Heinemann et al. ${ }^{19}$ (2006) found accidental bridge detachments with temporary cements to be rapid and frequent, and that improvements in retention and leakage can be attained by adding varnish to the temporary cements, thus reducing microleakage. ${ }^{20}$

Although the interim post and core crowns in the presented groups showed significant coronal leakage in vitro, the use of provisional cements, according to Markowitz et al. ${ }^{21}$ (1992), may inhibit ingress of bacteria from the mouth and consequent infection of the root canal. However, sealed root canals can be recontaminated under several circumstances, such as breaking the seal of the temporary filling material, or if filling materials and/or tooth structures become fractured or dislodged. Fox and Gutteridge ${ }^{1}$ (1997) showed that interim post and core crowns had significantly greater coronal leakage than prefabricated posts and casts. Their studies agree with Monday and Blais ${ }^{16}$ (1985) who, in a study of interim acrylic crowns, noted poor marginal adaptation with this type of restoration. Also, Friedman et al..$^{15}$ (1986) noted that the amount of leakage associated 
with interim restorations increased over time, and recommended using them for as short a time as possible. As shown by Torabinejad et al. ${ }^{14}$ (1990), reinfection of root canals can be rapid and, in situations where post spaces are found, the reinfection can be even faster. ${ }^{22}$ So, if temporary post and core crowns are lost, become dislodged, or are kept in place for an extended period of time, root canal retreatment should be considered.

Despite the limitations of the present work, ${ }^{23,24}$ the results call attention to the care that must be taken with this type of restoration, both during and after endodontic therapy. As suggested by a literature review, ${ }^{4}$ the prognosis of root canal-treated teeth can be improved by sealing the canal and min-

\section{References}

1. Fox K, Gutteridge DL. An in vitro study of coronal microleakage in root-canal-treated teeth restored by the post and core technique. Int Endod J. 1997 Nov;30(6):361-8.

2. Odabas ME, Tulunoglu O, Ozalp SO, Bodur H. Microleakage of different temporary filling materials in primary teeth. J Clin Pediatr Dent. 2010 Winter;34(2);157-60.

3.Ciftçi A, Vardarli DA, Sönmez IS. Coronal microleakage of four endodontic temporary restorative materials: an in vitro study. Oral Surg Oral Med Oral Pathol Oral Radiol Endod. 2009 Oct;108(4):e67-7.

4. Heling I, Gorfil C, Slutzky H, Kopolovic K, Zalkind M, Slutzky-Goldberg I. Endodontic failure caused by inadequate restorative procedures: review and treatment recommendations. J Prosthet Dent. 2002 Jun;87(6):674-8.

5. Gilbert SD, Witherspoon DE, Berry CW. Coronal leakage following three obturation techniques. Int Endod J. 2001 Jun;34(4):293-9.

6. Kremeier K, Fasen L, Klaiber B, Hofmann N. Influence of endodontic post type (glass fiber, quartz fiber or gold) and luting material on push-out bond strength to dentin in vitro. Dent Mater. 2008 May;24(5):660-6.

7. Balkenhol M, Wostmann B, Rein C, Ferger P. Survival time of cast post and cores: a 10-year retrospective study. J Dent. 2007 Jan;35(1):50-8.

8. Salvi GE, Siegrist Guldener BE, Amstad T, Joss A, Lang NP. Clinical evaluation of root filled teeth restored with or without post-and-core systems in a specialist practice setting. Int Endod J. 2007 Mar;40(3):209-15.

9. Isidor F, Brondum K, Ravnholt G. The influence of post length and crown ferrule length on the resistance to cyclic loading of bovine teeth with prefabricated titanium posts. Int J Prosthodont. 1999 Jan-Feb;12(1):78-82. imizing the leakage of oral fluids and bacteria into the periradicular areas as soon as possible after the completion of root canal therapy. Therefore, dental structure should be preserved as much as possible when making custom made posts, and the interim post and core crowns should be used only for short periods.

\section{Conclusion}

Teeth restored with interim post and core crowns will suffer leakage, and the length of the leakage depends on the amount of dental reminiscent. Rely X Temp NE and Hydro C cement have similar sealing capability when used with interim post and core crowns.

10. Rosen H. Dissolution of cement, root caries, fracture, and retrofit of post and cores. J Prosthet Dent. 1998 Oct;80(4):5113.

11. Madarati A, Rekab MS, Watts DC, Qualtrough A. Timedependence of coronal seal of temporary materials used in endodontics. Aust Endod J. 2008 Dec;34(3):89-93.

12. Lepe X, Bales DJ, Johnson GH. Retention of provisional crowns fabricated from two materials with the use of four temporary cements. J Prosthet Dent.1999 Apr;81(4):469-75.

13. Nomoto R, McCabe JF. A simple acid erosion test for dental water-based cements. Dent Mater. 2001 Jan;17(1):53-9.

14. Torabinejad M, Ung B, Kettering JD. In vitro bacterial penetration of coronally unsealed endodontically treated teeth. J Endod. 1990 Dec;16(12):566-9.

15. Friedman S, Shani J, Stabholz A, Kaplawi J. Comparative sealing ability of temporary filling materials evaluated by leakage of radiosodium. Int Endod J. 1986 Jul;19(4):187-93.

16. Monday JJ, Blais D. Marginal adaptation of provisional acrylic resin crowns. J Prosthet Dent. 1985 Aug;54(2):194-7.

17. Oddoni PG, Mello I, Coil JM, Antoniazzi JH. Coronal and apical leakage analysis of two different root canal obturation systems. Braz Oral Res. 2008 Jul-Sep;22(3):211-5.

18. Osborne JW, Swartz ML, Goodacre CJ, Phillips RW, Gale EN. A method for assessing the clinical solubility and disintegration of luting cements. J Prosthet Dent. 1978 Oct;40(4):413-7.

19. Heinemann F, Mundt T, Biffar R. Retrospective evaluation of temporary cemented, tooth and implant supported fixed partial dentures. J Craniomaxillofac Surg. 2006 Sep;34 Suppl 2:86-90.

20. Lewinstein I, Fuhrer N, Ganor Y. Effect of a fluoride varnish on the margin leakage and retention of luted provisional crowns. J Prosthet Dent. 2003 Jan;89(1):70-5. 
- Seal capability of interim post and core crown with temporary cements

21. Markowitz K, Moynihan M, Liu M, Kim S. Biologic properties of eugenol and zinc oxide-eugenol. A clinically oriented review. Oral Surg Oral Med Oral Pathol. 1992 Jun;73(6):72937.

22. Lyons WW, Hartwell GR, Stewart JT, Reavley B, Appelstein C, Lafkowitz S. Comparison of coronal bacterial leakage between immediate versus delayed post-space preparation in root canals filled with Resilon/Epiphany. Int Endod J. 2009 Mar;42(3):203-7.

23. Pommel L, Camps J. Effects of pressure and measurement time on the fluid filtration method in endodontics. J Endod. 2001 Apr;27(4):256-8.

24. Oliver CM, Abbott PV. Correlation between clinical success and apical dye penetration. Int Endod J. 2001 Dec;34(8):63744. 